\title{
MOTILITY OF ENTEROCOCCI ISOLATED FROM THE URINARY TRACT AND FROM OTHER SOURCES
}

\author{
R. D. BRANSBY AND R. N. GRÜNEBERG \\ Department of Clinical Microbiology, University College Hospital, London WC1E 6AU
}

\begin{abstract}
SUMmary. The identity and motility of enterococci isolated as urinary pathogens were compared with those of strains from other sources. The majority of isolates from all sources proved to be Streptococcus faecalis or S. faecium but eight of 117 urinary strains and seven of 127 non-urinary strains belonged to a group intermediate between $S$. faecalis and $S$. faecium. Of the seven "intermediate" strains from non-urinary sources, four were motile. None of the urinary enterococci was motile. The results do not indicate that urinary enterococci are more likely to be motile than are non-urinary strains.
\end{abstract}

\section{INTRODUCTION}

Urinary-tract pathogens are generally derived from the aerobic microbial flora of the intestine. The large majority of organisms causing urinary-tract infection are gram-negative rods, and most of them are motile. Enterococci are responsible for $2-4 \%$ of urinary-tract infections in general practice and 3-5\% in hospital (Grüneberg, 1980).

This study had two aims: to identify the enterococci isolated from patients with urinary-tract infection and from other sources, because motile strains investigated by other authors (Shattock, 1955; Graudal, 1957; Langston, Gutierrez and Bouma, 1960; Lund, 1967) have shown characteristics intermediate between Streptococcus faecalis and S. faecium; and to compare the proportion of motile isolates obtained from the urinary tract and from other sources.

\section{MATERIALS AND METHODS}

From urinary-tract infections, 117 strains were isolated in pure culture; from other sources such as faeces, wound swabs, high-vaginal swabs and cervical swabs, 127 isolates were also investigated. All isolates were categorised as gram-positive cocci, catalase negative and aesculin positive, and were subcultured on nutrient-agar slopes for storage at room temperature.

TABLE I

Expected biochemical reactions of group-D streptococci

\begin{tabular}{|c|c|c|c|c|c|c|c|}
\hline \multirow[b]{2}{*}{ Species } & \multirow{2}{*}{$\begin{array}{c}\text { Survival at } \\
60^{\circ} \mathrm{C} \\
30 \mathrm{~min}\end{array}$} & \multirow{2}{*}{$\begin{array}{l}\text { Growth in } \\
\mathrm{NaCl}\end{array}$} & \multicolumn{3}{|c|}{ Production of acid from } & \multirow{2}{*}{$\begin{array}{l}\text { Reduction of } \\
\text { tellurite }\end{array}$} & \multirow{2}{*}{$\begin{array}{l}\text { Utilisation } \\
\text { of citrate }\end{array}$} \\
\hline & & & inulin & mannitol & sucrose & & \\
\hline Streptococcus faecalis & + & + & - & + & + & + & + \\
\hline S. faecium & + & + & - & $\mathrm{V}$ & $\mathrm{V}$ & - & - \\
\hline S. avium & + & + & V & + & + & $\ldots$ & $\ldots$ \\
\hline \multicolumn{8}{|l|}{ S. faecium var. } \\
\hline casseliflavus & V & + & V & + & + & $\ldots$ & $\cdots$ \\
\hline S. bovis & - & - & + & V & + & $\ldots$ & $\ldots$ \\
\hline S. equinus & - & - & V & - & + & $\ldots$ & $\cdots$ \\
\hline
\end{tabular}

$+=$ Most strains positive; $-=$ most strains negative; $V=$ some strains positive, some strains negative; $\ldots=$ test not done. 
Further characterisations included tests of growth in $6.5 \% \mathrm{NaCl}$, resistance to heat at $60^{\circ} \mathrm{C}$ for $30 \mathrm{~min}$, fermentation of inulin, mannitol and sucrose, reduction of tellurite, and utilisation of citrate. The expected biochemical reactions are shown in table I.

All of the isolates were tested for motility, which was demonstrated by inoculation of Brain Heart Infusion Broth (Oxoid) with $0.025 \mathrm{ml}$ of an overnight broth culture and incubation at room temperature for 15-20 h; Graudal and Birch-Andersen (1958) found these conditions to be optimal for the development of motility. Growth was vigorous and motility was observed by

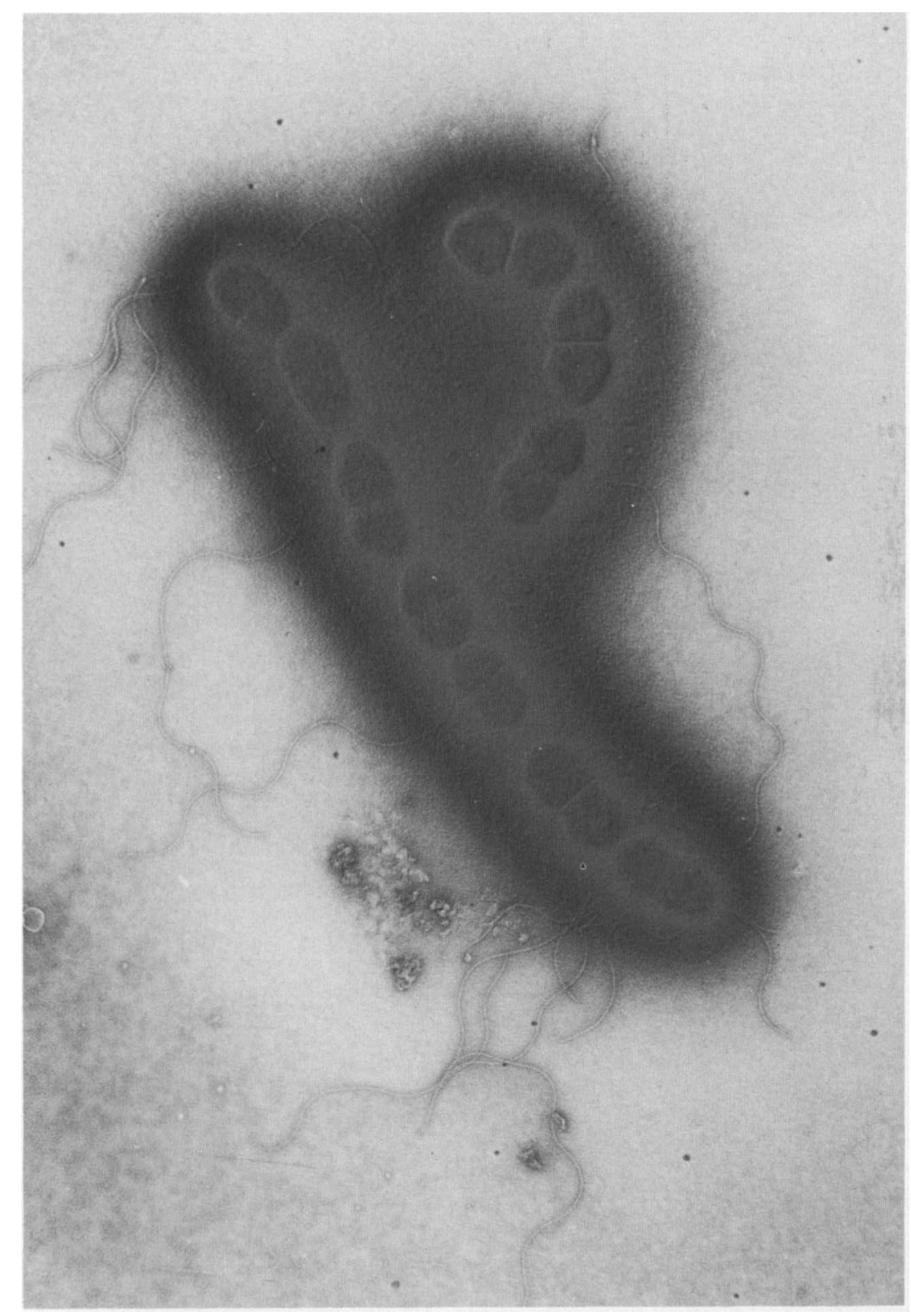

FIGURE.-Motile streptococci showing chains with flagella. 
direct microscopy of living cells. Mutation to non-motile variants has not been recorded and so it was expected that motility would be a stable and reproducible characteristic.

\section{RESULTS}

\section{Urinary-tract isolates}

Of 117 strains investigated, 96 were $S$. faecalis, 13 were $S$. faecium and eight were intermediate; in that they reduced tellurite but did not utilise citrate (table II). Motile strains were not isolated from the urinary tract.

\section{Isolates from other sources}

Of 127 isolates, 90 were $S$. faecalis, 23 were $S$. faecium, seven were not enterococci and seven were of the intermediate type (table II). Four motile strains were isolated (see the figure); according to our classification these were all of the intermediate type in that they reduced tellurite but did not utilise citrate as a source of energy. Colonies of two of these isolates were $\alpha$ haemolytic and non-pigmented and two produced non-haemolytic yellow colonies.

TABLE II

Comparison of isolates from different sources

\begin{tabular}{l|rc}
\hline \multirow{2}{*}{ Species } & \multicolumn{2}{c}{ Number (and percentage) of isolates from } \\
\cline { 2 - 3 } & urinary tract & other sources \\
\hline $\begin{array}{l}\text { S. faecalis } \\
\text { S. faecium }\end{array}$ & $96(82)$ & $90(75)$ \\
Intermediate types & $13(11)$ & $23(19)$ \\
All & $8(7)$ & $7 *(6)$ \\
Not enterococci & 117 & 120 \\
(excluded) & 0 & 7 \\
\hline
\end{tabular}

* Four strains were motile.

\section{DISCUSSION}

The occurrence of motile streptococci was recognised by Billroth (1874). From the 1950s various studies of motile streptococci have led to their being classified as culturally and biochemically intermediate between $S$. faecalis and $S$. faecium or bearing a closer similarity to the latter than the former. In our study, the majority $(82 \%)$ of 117 strains isolated from the urinary tract were $S$. faecalis. Of the remainder, $13(11 \%$ of the total) were $S$. faecium and only 8 $(7 \%)$ could be classified as intermediate. None of the enterococci causing urinary-tract infection was motile.

The isolates from other sources can all be considered as being primarily of faecal origin, but the proportions of the species that we encountered cannot be considered as indicative of their proportion in faeces or, indeed, in the population at large. In our selection of these strains, no attempt was made either to count the numbers present or to ensure that all of the enterococci in a specimen were selected. Strains were merely picked at random from a range of specimens to provide a sample of enterococci from which we could determine the proportion of motile strains. Of the 120 enterococci isolated from non-urinary sources, $S$. faecalis was again the most numerous $(75 \%)$, but $S$. faecium was isolated more often $(19 \%)$ than from the urinary tract $(11 \%)$. Seven isolates $(6 \%)$ were considered to be intermediate between $S$. faecalis and $S$. faecium; four of these were motile.

Thus, of the 120 isolates from other sources four ( $3.3 \%$ ), all of intermediate type, were motile, whereas none of the 117 urinary isolates was motile. This does not suggest that urinary enterococci are more likely to be motile than are non-urinary strains. 
We are grateful to our colleagues in the laboratories at University College Hospital for their assistance in this work. The study represented part of a dissertation submitted to the University of London for the MSc. degree by R.D.B.

\section{REFERENCES}

BILlROTH, T. 1874. Untersuchungen über die Vegetationsformen von Coccobacteria septica, Reimer, Berlin.

Graudal, H. 1957. The classification of motile streptococci within the enterococcus group. Acta path. microbiol. scand., 41, 403.

Graudal, H. AND BirCh-ANDERSEN, A. 1958. Studies on the motility and flagellation of a motile streptococcus. Acta path. microbiol. scand., 43, 185.

GrünEBERG, R. N. 1980. Antibiotic sensitivities of urinary pathogens, 1971-8. J. clin. Path., 33, 853 .

Langston, C. W., Gutierrez, J. And Bouma, C. 1960. Motile enterococci (Streptococcus faecium var. mobilis var. n.) isolated from grass silage. J. Bact. 80, 714.

LuND, B. M. 1967. A study of some motile group D streptococci. J. gen. Microbiol., 49, 67.

Shatтock, P. M. F. 1955. The identification and classification of Streptococcus faecalis and some associated streptococci. Annls Inst. Pasteur Lille, 7, 95. 